\title{
Metastability and fatigue behavior of austenitic stainless steels
}

\author{
Marek Smaga $^{1^{*}}$, Annika Boemke, Tobias Daniel, Matthias W. Klein ${ }^{1}$ \\ ${ }^{1}$ University of Kaiserslautern, Institute of Materials Science and Engineering, Kaiserslautern, Germany
}

\begin{abstract}
This study presents the results of a detailed investigation of metastability and susceptibility to deformation induced $\alpha$ '-martensite formation of several austenitic steels (AISI 304, AISI 321, AISI 348 and two batches from AISI 347) in the solution-annealed state. Besides conventional characterization of metastability by calculating stacking-fault energy and threshold temperature (designated as $\mathrm{M}_{\mathrm{S}}$ and $\mathrm{M}_{\mathrm{d} 30}$ ), the present work introduced a new method for determining susceptibility to $\alpha$-martensite formation. The method was based on dynamically applied local plastic deformation and non-destructive micro-magnetic measurement of $\alpha$ '-martensite content. The parameter $I_{\xi}$ was established, which correlated very well with the grade of $\alpha$-martensite formation during cyclic loading. The cyclic deformation and phase transformation behavior of cyclically loaded specimens from different metastable austenitic steels were investigated in total-strain and stress controlled fatigue tests with load ratio $\mathrm{R}=-1$ at ambient temperature. The influence of the strain rate on the cyclic deformation and phase transformation behavior was also examined. During the fatigue tests, besides stress-strain hysteresis and temperature measurement, in situ micro-magnetic measurements were performed. Using the compressive measured data, the influence of plastic induced self-heating of the specimen and the strain rate on $\alpha^{\prime}$-martensite formation was analyzed.
\end{abstract}

\section{Introduction}

Fatigue is a process of mechanical failure resulting from the application of repeated cyclic loading with stresses mostly below stress limit determinates in monotonic tensile tests [1]. To enhance the monotonic and especially cyclic strength of metallic materials, microstructural modification is possible due to chemical alloying and heat treatment. Accordingly, crystallographically structured steels can be divided into two classes: (i) steels with a body-centered cubic (bcc) structure and (ii) steels with a face-centered cubic (fcc) structure [2]. The second class comprises austenitic steels, which were discovered to obtain a passivity (and, hence, "stainlessness"). Since the chromium contents of typical austenitic stainless steels exceed $16 \mathrm{wt} \%$, their equilibrium microstructure at room temperature would be fully ferritic, if no other austenite-stabilizing alloying elements were added to the material. The elements most often used to obtain an austenitic microstructure are nickel, manganese, carbon and nitrogen [3]. However, changes in chemical composition not only influence the passivity of austenitic stainless steel but also significantly affect the metastability of the austenitic microstructure [4-7].

As is very well known, a huge number of austenitic stainless steels of the AISI 300 series exist in the metastable state [8-10]. These steels transform due to plastic deformation from paramagnetic austenite to a more stable microstructure, i.e. paramagnetic $\varepsilon$ - martensite and/or ferromagnetic $\alpha^{\prime}$-martensite. The process of deformation induced phase transformation is presented in figure 1. Figure 1a shows a purely austenitic microstructure of AISI 304 in the solution-annealed state. Due to monotonic loading at ambient temperature up to $\varepsilon=8 \%$ elongation, a deformation induced phase transformation from $\gamma$-austenite to $\alpha$-martensite occurred, which can be clearly observed in the micrograph presented in Fig. 1b. Further mechanical loading leads to an increase in the volume fraction of $\alpha$ 'martensite. The deformation-induced $\alpha$ '-martensite is clearly visible as dark needles embedded in the yellowcolored austenite grains (Fig. 1b and c). This clarifies that plastic deformation of metastable austenite at ambient temperature leads to significant changes in phase distribution from single-phase austenitic (Fig. 1a) to two-phase $\gamma$-austenite/ $\alpha$-martensite microstructures (Fig. $1 \mathrm{~b}$ and $\mathrm{c}$ ). (a)

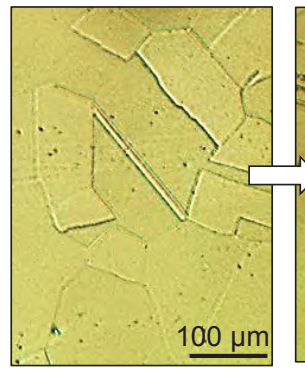

(b)

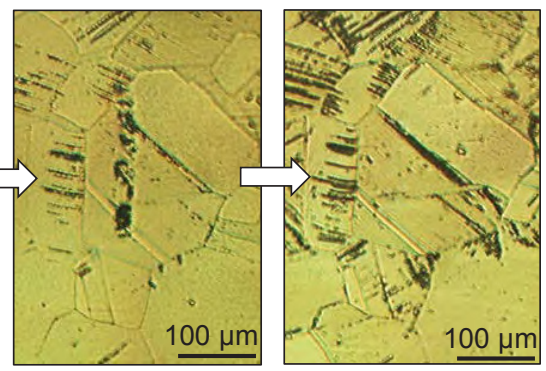

Corresponding author: smaga@mv.uni-kl.de 
Fig. 1. Deformation induced $\alpha^{\prime}$-martensite formation in metastable austenitic steel AISI 304 during tensile loading initial state (a), $8 \%$ (b) and $12 \%$ (c) elongation

Because, the fcc austenite has a lower strength compared to the bcc $\alpha$-martensite [11], it can be defined as the matrix and the $\alpha^{\prime}$-martensite as reinforcements of a "dynamically composite material" with a changing volume fraction and distribution of $\alpha$ '-martensite during mechanical monotonic and cyclic loading. Because $\alpha^{\prime}-$ martensite formation leads to cyclic hardening, and this formation consequently influences significantly the fatigue life of metastable austenitic steels [11-22], it is important to have a reliable method for determining susceptibility to deformation induced $\alpha^{\prime}$-martensite formation. The susceptibility depends generally on two parameters: (i) the metastability of the initial austenitic microstructure, as a function of its chemical composition [4-7] and grain size [23], and (ii) the loading conditions such as load temperature [16, 19-20] and deformation rate [22].

In this study, the metastability of six austenitic stainless steels (AISI 304, AISI 321, AISI 348 and two batches from AISI 347) were characterized by calculating stacking-fault energy (SFE) and $\mathrm{M}_{\mathrm{S}}$ and $\mathrm{M}_{\mathrm{d} 30}$ temperature. Further, a new method for determining susceptibility to deformation induced $\alpha$ '-martensite formation in metastable austenitic stainless steels was developed and applied to specimens based on dynamically applied local plastic deformation of metastable austenite and non-destructive micro-magnetic measurements. The influence of metastability and load conditions on deformation induced $\alpha^{\prime}$-martensite formation and cyclic deformation behavior were investigated and analyzed during total strain control fatigue tests.

\section{Material and methods}

\subsection{Austenitic stainless steels}

The chemical composition of investigated austenitic stainless steels is summarized in table 1. AISI 304 is a typical reference for so-called 18/10 stainless steels with $18 \mathrm{wt} \% \mathrm{Cr}$ and $10 \mathrm{wt} \% \mathrm{Ni}$. AISI 321 is titanium-alloyed $(\% \mathrm{Ti} \geq 5 . \% \mathrm{C})$ austenitic steel. Due to a higher affinity between carbon and titanium, compared to chromium, titanium carbides develop in the microstructure and arrest the carbon content. Hence, chromium carbide formation, which can result in chromium depletion at the grain boundaries, is depressed. Consequently, there can be an increase in intergranular corrosion resistance in AISI 321. A similar concept is used for niobium-alloyed $(\% \mathrm{Nb} \geq 10 \% \mathrm{C}$ ) austenitic steels. In this case niobium carbides develop and arrest the carbon content, which is no longer in solution in austenite, for the formation of chromium carbides [3]. AISI 348 and 347 are niobiumalloyed steels and practically have the same chemical composition (nominally the difference is in the $\mathrm{Nb}$ content). From a one hand it can be seen, that three investigated type of austenitic stainless steels (AISI 304,
321 and 348/347) differed generally in corrosion resistance, but for the another hand chemical composition significantly influenced the metastability of the austenite and its susceptibility to forming $\alpha^{\prime}$ -

\begin{tabular}{|l|c|c|c|c|c|}
\hline AISI & $\mathbf{3 0 4}$ & $\mathbf{3 2 1}$ & $\mathbf{3 4 8}$ & $\mathbf{3 4 7 a}$ & $\mathbf{3 4 7 b}$ \\
\hline $\mathbf{C}$ & 0.040 & 0.035 & 0.021 & 0.040 & 0.024 \\
\hline $\mathbf{N}$ & 0.008 & 0.008 & 0.009 & 0.007 & 0.019 \\
\hline $\mathbf{T i}$ & 0.01 & 0.30 & 0.01 & 0.02 & 0.02 \\
\hline $\mathbf{N b}$ & 0.02 & 0.03 & 0.36 & 0.62 & 0.41 \\
\hline $\mathbf{C r}$ & 18.3 & 17.6 & 17.4 & 17.6 & 17.3 \\
\hline $\mathbf{N i}$ & 8.2 & 9.3 & 9.3 & 10.6 & 9.3 \\
\hline $\mathbf{M n}$ & 1.40 & 1.45 & 1.47 & 1.83 & 1.55 \\
\hline $\mathbf{M o}$ & 0.18 & 0.23 & 0.34 & 0.29 & 0.19 \\
\hline $\mathbf{S i}$ & 0.36 & 0.56 & 0.54 & 0.41 & 0.63 \\
\hline
\end{tabular}

martensite even for the same type of austenitic steel (see section 3.1).

Table 1. Chemical composition in weight \%

Table 2 summarizes the monotonic mechanical properties, hardness, as well as volume fraction of $\alpha$-martensite after specimen failure for all the investigated austenitic stainless steels. The specimens were examined after solution-annealed heat treatment, taken from bars with a diameter of $20 \mathrm{~mm}$ (AISI 304, 321,348 ) [16] and $25 \mathrm{~mm}$ (AISI 3457b) [11]. The following heat treatment parameters were used: $1050^{\circ} \mathrm{C}$ for $35 \mathrm{~min}$ followed by quenching in helium atmosphere. The AISI $347 \mathrm{a}$ specimen was taken from an original surge pipeline component with an outer diameter of $333 \mathrm{~mm}$ and wall thickness of $36 \mathrm{~mm}$ [17] and solution annealed at $1050^{\circ} \mathrm{C} / 10 \mathrm{~min} / \mathrm{H}_{2} \mathrm{O}$.

Table 2. Mechanical properties, hardness and $\alpha$ '-martensite after specimen failure $(\xi)$

\begin{tabular}{|l|c|c|c|c|c|}
\hline AISI & $\mathbf{3 0 4}$ & $\mathbf{3 2 1}$ & $\mathbf{3 4 8}$ & $\mathbf{3 4 7 a}$ & $\mathbf{3 4 7 b}$ \\
\hline $\mathrm{R}_{\mathrm{p} 0.2}$ in MPa & 241 & 209 & 243 & 242 & 220 \\
\hline UTS in MPa & 677 & 641 & 640 & 569 & 621 \\
\hline A in $\%$ & 84 & 65 & 62 & 66 & 51 \\
\hline $\mathrm{HV} 10$ & 208 & 176 & 177 & 140 & 152 \\
\hline$\xi$ in FE-\% & 9.4 & 23.4 & 25.3 & 4.4 & 33.2 \\
\hline
\end{tabular}

\subsection{Method for determining susceptibility to the formation of deformation induced $\alpha^{\prime}$ - martensite}

Susceptibility to the formation of deformation induced $\alpha$-martensite in austenitic stainless steels at constant temperature, e.g. ambient temperature (AT), depends on both chemical composition, therefore the stacking-fault energy (SFE), and the local microstructure state, such as grain size or dislocation density. The influence of chemical composition on austenite metastability has been intensively investigated in the literature [4-7] and several empirical equations are given to calculate SFE and $\mathrm{M}_{\mathrm{S}}$ and $\mathrm{M}_{\mathrm{d} 30}$ temperature (see section 3.1). For calculations of the aforementioned metastability parameters, a homogenous distribution of chemical composition in the microstructure was assumed. But even after solution-annealing heat treatment, a local heterogeneity of chemical composition exists in the 
microstructure, which strongly influences the local formation of $\alpha^{\prime}$-martensite [7, 9-10]. Additionally, the same chemical composition can be obtained for austenitic stainless steels with higher dislocation density, e.g. after cold rolling or for austenitic microstructures with a comparatively smaller dislocation density e.g. after warm rolling. The ratio of cold hardening, before $\alpha^{\prime}$-martensite formation, is not included in the aforementioned parameters $\left(\mathrm{M}_{\mathrm{d} 30}, \mathrm{M}_{\mathrm{S}}, \mathrm{SFE}\right)$ but significantly influences the stress-strain behavior and $\alpha^{\prime}$ martensite formation during monotonic and especially cyclic loading of metastable austenitic steels. Therefore, in order to determine the susceptibility of the formation of deformation induced $\alpha^{\prime}$-martensite in austenitic stainless steels an investigative method is required which includes both the influence of the chemical composition and the stress-strain state of the material. One possibility is to use a Poldi hardness tester (Fig. 2a) to make a local plastic deformation, and to perform micro-magnetic measurements by e.g. Feritscope ${ }^{\mathrm{TM}}$ sensor (Fig. 2c).
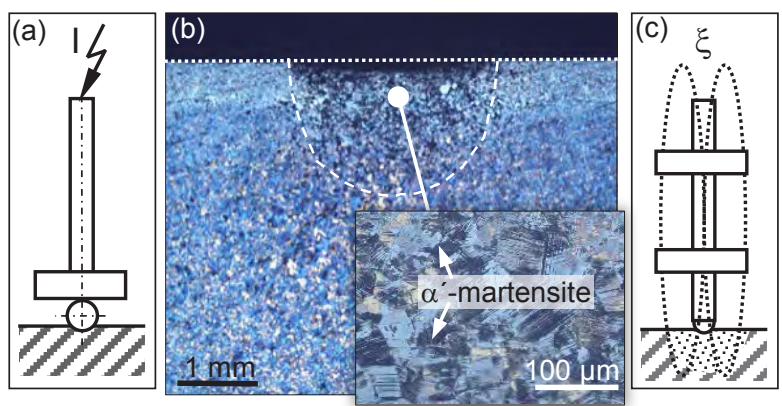

Fig. 2. Local plastic deformation after dynamic hardness test showed schematically in (a), optical micrograph with $\alpha$ '-martensite in metastable matrix after dynamic loading of AISI 348 (b) and Feritscope ${ }^{\mathrm{TM}}$ measurements principle (c)

The Poldi hardness tester was used to make a local plastic deformation in a flat specimen. Independently of the chemical based metastability of austenite (SFE) and the local microstructural state (grain size, dislocation density, etc.), the metastable austenite transformed more or less into stable $\alpha$ '-martensite by applied dynamic load at constant temperature e.g. ambient temperature. For the Poldi hardness test a special Brinell ball of $10 \mathrm{~mm}$ diameter was used resulting in relatively higher impact forces in comparison to static hardness tests. The plastic deformation occurred in the range of several millimeters (Fig. 2b). This range of plastic deformation is sufficiently high enough to average out the local inhomogeneity in chemical composition as well as in grain size, which occurred within the deformation zone. Hence the real local microstructural state (workhardened or solution annealed) can be tested. After impact loading, micro magnetic measurements using a Feritscope $^{\mathrm{TM}}$ sensor were performed. Because the $\alpha^{\prime}$ martensite is ferromagnetic, the volume fraction of $\alpha^{\prime}-$ martensite could be nondestructively measured, which directly correlated with the susceptibility of deformation induced $\alpha^{\prime}$-martensite formation. The results from these tests are shown in section 3.1.

\subsection{Fatigue setup}

For the cycle-dependent recording of mechanical hysteresis loops, an extensometer (A) was fixed to the gauge length. The specimens were clamped in

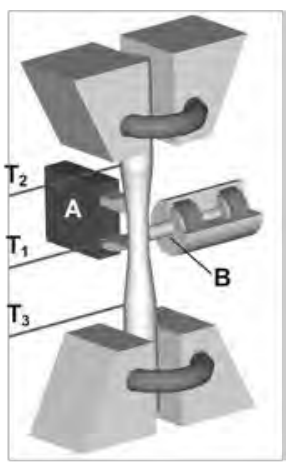

$$
\Delta T=T_{1}-0.5 \cdot\left(T_{2}+T_{3}\right)
$$

A: extensometer

B: $\quad$ Feritscope $^{\mathrm{TM}}$

$\mathrm{T}_{1}-\mathrm{T}_{3}$ : thermocouples

Fig. 3. Experimental setup for fatigue tests using measurement methods

thermostatically-controlled wedge grips.

Three thermocouples $T_{1}-T_{3}$ were used for highlyaccurate temperature measurements. The temperature changes $\Delta \mathrm{T}$ were only caused by plastic deformation in the gauge length. The volume fraction of $\alpha^{\prime}$-martensite was detected in situ with a Feritscope ${ }^{\mathrm{TM}}$ sensor (B). During testing, the probe was attached to the specimen and energized by a low-frequency magnetic field in order to form a magnetic circuit. This field induced a voltage in the testing probe coil as a direct measurement of the permeability. The Feritscope ${ }^{\mathrm{TM}}$ magnetic fraction $(\xi)$ is given in volume percent ferrite (FE\%), without converting into $\alpha^{\prime}$-martensite content. In the literature, a linear correlation between $\mathrm{FE} \%$ and $\alpha^{\prime}$-martensite content is reported [24]. To investigate the cyclic deformation behavior and the formation of deformation induced $\alpha$ '-martensite, specimens with a gauge length of $15 \mathrm{~mm}$ and diameter of $7.6 \mathrm{~mm}$ were used.

\section{Results}

\subsection{Metastability of austenitic stainless steels and susceptibility to the formation of deformation induced $\alpha^{\prime}$-martensite}

Metastabilty of metastable austenitic steels is mainly influenced by the chemical composition [4-7]. Hence, several empirically determined equations for calculating stacking-fault energy (SFE) and $\mathrm{M}_{\mathrm{S}}$ and $\mathrm{M}_{\mathrm{d} 30}$ temperature thresholds have been developed to estimate the metastabilty of austenite. $\mathrm{M}_{\mathrm{S}}$ temperature is the temperature at which spontaneous thermally induced austenite-martensite transformation without plastic deformation occurs [6]. The so-called $\mathrm{M}_{\mathrm{d} 30}$ temperature is used for plasticity-induced martensite formation. At $\mathrm{M}_{\mathrm{d} 30}$ temperature, by definition, $50 \% \alpha^{\prime}$-martensite is formed as a result of $30 \%$ deformation [4, 5] Calculating the values of the $\mathrm{SFE}, \mathrm{M}_{\mathrm{S}}$ and $\mathrm{M}_{\mathrm{d} 30}$ temperatures, according to the following equations, provides table 3 .

$$
\begin{aligned}
\mathrm{M}_{\mathrm{d} 30, \text { Angel }} \text { in }{ }^{\circ} \mathrm{C}= & 413-462 \cdot(\mathrm{C}+\mathrm{N})-13,7 \cdot \mathrm{Cr}-9,5 \cdot \mathrm{Ni} \\
& -8,1 \cdot \mathrm{Mn}-18,5 \cdot \mathrm{Mo}-9,2 \cdot \mathrm{Si}[5]
\end{aligned}
$$




$$
\begin{aligned}
\mathrm{M}_{\mathrm{S}, \text { Eichelmann }} \text { in }{ }^{\circ} \mathrm{C}= & 1350-1665 \cdot(\mathrm{C}+\mathrm{N})-42 \cdot \mathrm{Cr}-61 \cdot \mathrm{Ni} \\
& -33 \cdot \mathrm{Mn}-28 \cdot \mathrm{Si}[6] \\
\mathrm{SFE} \text { in } \mathrm{mJ} / \mathrm{m}^{2}= & 25.7+2 \cdot \mathrm{Ni}-0.9 \cdot \mathrm{Cr}-1.2 \cdot \mathrm{Mn}+ \\
& 410 \cdot \mathrm{C} \\
& -77 \cdot \mathrm{N}-13 \cdot \mathrm{Si}[7]
\end{aligned}
$$

Table 3. SFE, $\mathrm{M}_{\mathrm{S}}$ and $\mathrm{M}_{\mathrm{d} 30}$ temperature

\begin{tabular}{|l|c|c|c|c|c|}
\hline \multicolumn{1}{|c|}{ AISI } & $\mathbf{3 0 4}$ & $\mathbf{3 2 1}$ & $\mathbf{3 4 8}$ & $\mathbf{3 4 7 a}$ & $\mathbf{3 4 7 b}$ \\
\hline $\mathrm{M}_{\mathrm{d} 30}$ in ${ }^{\circ} \mathrm{C}$ & 12 & 43 & 48 & 25 & 46 \\
\hline $\mathrm{M}_{\mathrm{S}}$ in ${ }^{\circ} \mathrm{C}$ & -171 & -91 & -66 & -189 & -81 \\
\hline SFE in $\mathrm{mJ} / \mathrm{m}^{2}$ & 35 & 33 & 28 & 39 & 27 \\
\hline
\end{tabular}

The $\mathrm{M}_{\mathrm{d} 30}$ temperature of the metastable austenitic steels AISI 304, 321, 348, 347a and 347b is shown in Fig. 4. Due to minimum $\mathrm{M}_{\mathrm{d} 30}$ temperature, AISI 304 was found to be more stable compared to titanium-alloyed AISI 321 and niobium-alloyed AISI 348 steels. The two batches of AISI 347 displayed a significant difference in metastability. AISI $347 \mathrm{a}$ had a small metastability, in the range of AISI 304, while AISI $347 \mathrm{~b}$ had a higher one, in the range of AISI 348. Dependent of which parameter (SFE, $\mathrm{M}_{\mathrm{S}}$ or $\mathrm{M}_{\mathrm{d} 30}$ temperatures) was used to determine the metastability of the specimens the differences between the types of austenitic stainless steels could be, more or less observed. It is important to note that the resulting temperatures were not absolute values. Their use was of a comparative kind, e.g. to compare steels or batches from different types of austenitic steels in terms of their susceptibility to austenite-martensite transformation. Hence, the method for determining susceptibility to the formation of deformation induced $\alpha^{\prime}$-martensite outlined in section 2.2 was used. Figure 4 summarizes the results from impact tests with subsequent Feritscope ${ }^{\mathrm{TM}}$ measurement. For each type/batch of austenitic stainless steels six different measurement points in the longitudinal section of the specimen were used. All sections before the impact loading showed $\xi=0.0 \mathrm{FE} \%$ due to mechanical and electrical polishing of the surface. The mean value of the $\alpha$ '-martensite measurement after impact loading was called $I_{\xi}$ and is plotted together with the standard deviation in Fig. 4.

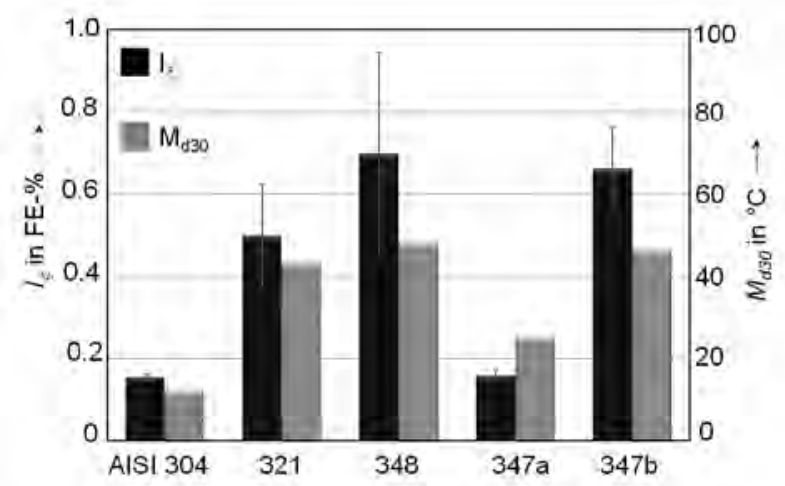

Fig. 4. $\mathrm{M}_{\mathrm{d} 30}$ temperatures as metastability parameter, and $\alpha$ '-martensite content $\left(\mathrm{I}_{\xi}\right)$ after impact tests as a susceptibility parameter to deformation induced $\alpha$ '-martensite formation of all investigated austenitic stainless steels

\subsection{Influences of metastability on $\alpha^{\prime}$ - martensite formation and cyclic deformation behavior}

Fatigue behavior of metastable austenitic steels at temperatures up to the martensite deformation temperature is strongly influenced by cyclically induced $\alpha$-martensite formation. In respect of specimens AISI 304, AISI 321 and AISI 348 (tested under cyclic loading with total-strain amplitude $\varepsilon_{\mathrm{a}, \mathrm{t}}=1 \%$ and load frequency $\mathrm{f}=0.2 \mathrm{~Hz}$ ) the following results are presented: figure 5a shows the resulting stress amplitude $\left(\sigma_{\mathrm{a}}\right)$; figure $5 \mathrm{~b}$ shows the development of ferromagnetic fraction of $\alpha$-martensite $(\xi)$ measured in situ by Feritscope $^{\mathrm{TM}}$, and figure $5 \mathrm{c}$ displays the change in temperature $(\Delta T)$ due to change in the strain energy density per specific volume, correlating with the area of stress-strain hysteresis.
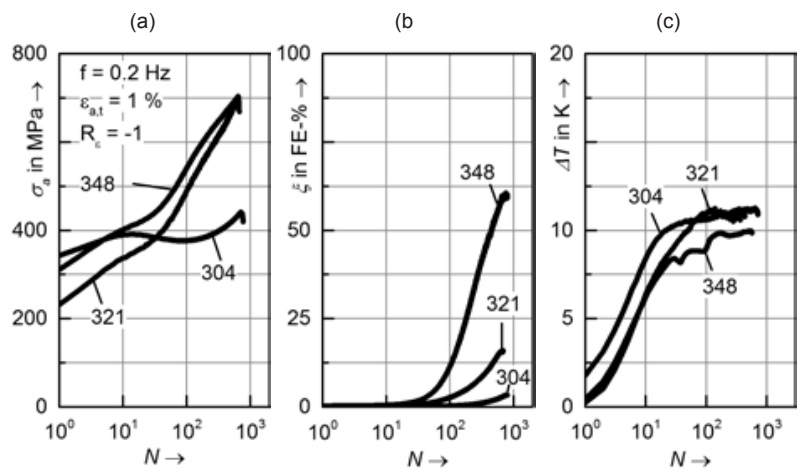

Fig. 5. $\sigma_{\mathrm{a}}-\mathrm{N}(\mathrm{a}), \xi-\mathrm{N}(\mathrm{b})$ and $\Delta \mathrm{T}-\mathrm{N}$ (c) curves from total strain controlled fatigue tests, $\varepsilon_{\mathrm{a}, \mathrm{t}}=1 \%, \mathrm{f}=0.2 \mathrm{~Hz}$ for AISI 304, AISI 321 and AISI 348

Clearly, the formation of $\alpha^{\prime}$-martensite led to pronounced cyclic hardening. The susceptibility to the formation of cyclic deformation induced $\alpha^{\prime}$-martensite correlated very well with metastability and susceptibility $I_{\xi}$ parameters (see section 3.1). According to the $I_{\xi}, M_{d 30}$ and $\mathrm{M}_{\mathrm{S}}$ temperatures as well as SFE of the investigated metastable austenite, the AISI 304 steel formed less $\alpha^{\prime}$ martensite during cyclic loading compared to the titanium-alloyed AISI 321 and the niobium-alloyed AISI 348 steels. After a material-dependent number of cycles $\mathrm{N}$, the formation of $\alpha^{\prime}$-martensite commenced and increased continuously with increasing number of cycles up to specimen failure. Maximum value of $\alpha$ '-martensite $(\xi=60 \mathrm{FE} \%$ ) was observed for AISI 348 at specimen failure. AISI 321 achieved $\xi=15 \mathrm{FE} \%$ at specimen failure but AISI 304 only $\xi=4 \mathrm{FE} \%$. The $\sigma_{\mathrm{a}}-\mathrm{N}$ curves (Fig. 5a) describe the cyclic deformation behavior of these three metastable austenitic stainless steels in detail. The stress amplitude of AISI 304 and AISI 348 commenced at a comparable value of $\sigma_{\mathrm{a}}$ while AISI 321 shows a lower value, which correlated with the monotonic determinate $\mathrm{R}_{\mathrm{p} 0.2}$ limits (see table 2). Further cyclic loading led to cyclic hardening due to increased dislocation density [16] for all materials up to approximately ten cycles. While for the more metastable AISI 348 and AISI 321 steels a continuous increase in stress amplitude was observed, the less metastable AISI 
304 showed a softening process with a decrease in stress amplitude, up to approximately 100 cycles. A secondary cyclic hardening in AISI 304 could only be detected when the $\alpha$ '-martensite formed. Cyclic hardening of the AISI 321 / AISI 348 steels resulted in a maximum stress amplitude $\sigma_{\mathrm{a}}=700 / 710 \mathrm{MPa}$, which is higher than the tensile strength $\mathrm{R}_{\mathrm{m}}=641 / 640 \mathrm{MPa}$ of these materials. The $\Delta \mathrm{T}$-N-curves (Fig 5c) show the change in the specimens' temperatures during cyclic loading. $\Delta \mathrm{T}$ was determined as the difference between temperature in the middle of the specimen $\mathrm{T}_{1}$ and mean value of the temperature measured with two further thermocouples $\left(T_{2}\right.$ and $\left.T_{3}\right)$ fixed at the shafts of the specimens, where due to the comparatively thicker section only elastic deformation occurred (see Fig. 3). After the initial period (approximately ten cycles) with a significant increase of $\Delta \mathrm{T}$, the measured change in the specimens' temperature was in the range $9 \mathrm{~K}<\Delta \mathrm{T}<12 \mathrm{~K}$. For austenitic stainless steels this is a relatively small change in the temperature of the specimen (comp. Fig 5c with Fig. 8c), due to the relatively low frequency of $\mathrm{f}=0.2 \mathrm{~Hz}$. However, it is important to mention that for the development of $\alpha^{\prime}$-martensite not only is the change in temperature critical but so is the absolute temperature in the gauge length of the specimens. In these tests maximal temperatures were in the range $34{ }^{\circ} \mathrm{C}<\mathrm{T}_{1 \max }<$ $37^{\circ} \mathrm{C}$.
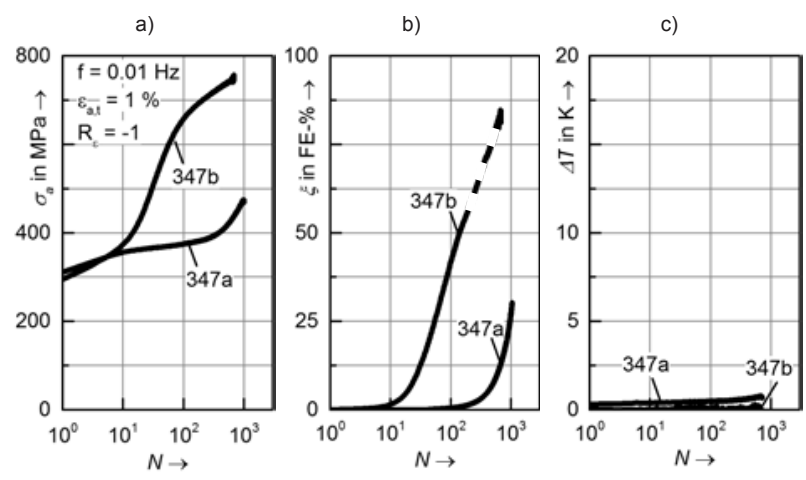

Fig. 6. $\sigma_{\mathrm{a}}-\mathrm{N}(\mathrm{a}), \xi-\mathrm{N}(\mathrm{b})$ and $\Delta \mathrm{T}-\mathrm{N}$ (c) curves from total strain controlled fatigue tests, $\varepsilon_{\mathrm{a}, \mathrm{t}}=1 \%, \mathrm{f}=0.01 \mathrm{~Hz}$, for AISI $347 \mathrm{a}$ and AISI $347 \mathrm{~b}$

To investigate the influence of metastability of nominally the same type of austenitic stainless steel, specimens from two batches of AISI 347 were examined. The specimens were cyclically loaded with total strain amplitude $\varepsilon_{\mathrm{a}, \mathrm{t}}=1 \%$ at very low frequency $\mathrm{f}=$ $0.01 \mathrm{~Hz}$ to keep their temperature at ambient level (see Fig. 6c) thereby eliminating the possible influence of temperature

$\alpha^{\prime}$-martensite formation. Figure 6 summarizes the results of these tests. Specimens from both batches showed a continuous cyclic hardening, however with different gradients after the first ten cycles. In the cycle range $10<\mathrm{N}<100$ AISI 347a showed only a slight increase of stress amplitude, while AISI $347 \mathrm{~b}$ underwent a larger increase of $\sigma_{a}$. AISI 347b's increase in $\sigma_{a}$ correlated directly with a significant development of $\alpha^{\prime}$-martensite (Fig. 6b) from $1 \mathrm{FE} \%$ to $41 \mathrm{FE} \%$. As mentioned in section 2, ferromagnetic $\alpha^{\prime}$-martensite was measured in situ during fatigue tests by Feritscope ${ }^{\mathrm{TM}}$ sensor, for which readings above $60 \mathrm{FE} \%$ could be due to instrument linearity and calibration difficulties at high $\alpha^{\prime}$-martensite contents. Therefore the measured data in the range above $60 \mathrm{FE} \%$ were plotted as dashed lines in Fig. 6b. After a high rate of $\sigma_{a}$ at cycles between $\mathrm{N}=10$ and $\mathrm{N}=100$, AISI $347 \mathrm{~b}$ showed a decrease in the stress amplitude rate $\mathrm{d \sigma}_{\mathrm{a}} / \mathrm{dN}$. However, further cyclic hardening took place which led to specimen failure at $\sigma_{\mathrm{a}}$ $=760 \mathrm{MPa}$, which is $120 \mathrm{MPa}$ higher than the tensile strength of this material (table 2). With respect to the other batch, AISI $347 \mathrm{a}$ also showed evidence of a correlation between the development of $\alpha^{\prime}$-martensite and an increase in stress amplitude. However, the start of the $\alpha^{\prime}$-martensite formation occurred at a higher number of cycles in comparison to AISI $347 \mathrm{~b}$ and the $\alpha$ martensite content was found to be, at the same number of cycles, significantly smaller with the maximum value at specimen failure $\xi=30 \mathrm{FE} \%$. The results of these tests clearly depicted how substantial the differences can be between the formation of deformation induced $\alpha^{\prime}$-martensite in the same type of austenitic stainless steels due to differences in chemical composition and consequently the metastability of austenite. It should be noted that both batches had a chemical composition in the range of international standards for this steel.

\subsection{Cyclic stress-strain behavior}

Illustrating the hardening potential of metastable austenitic stainless steels due to cyclic induced $\alpha^{\prime}$-martensite formation, figure 7 displays the monotonic and cyclic stress-strain (CSS) curves from the low carbon steel AISI 4140 in two different heat treatment conditions [25] and the investigated AISI 347a.
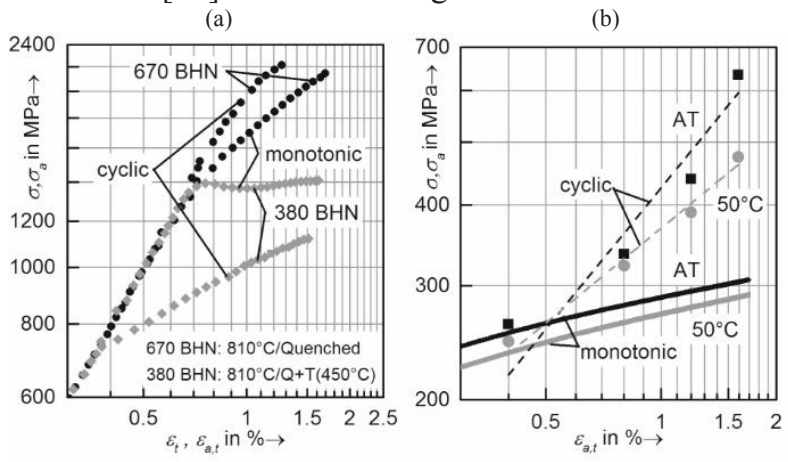

Fig. 7. Cyclic and monotonic stress-strain curves for AISI 4142 in tempered and in hardened state according [25] (a) and for AISI $347 \mathrm{a}$ at ambient temperature and at $50^{\circ} \mathrm{C}(\mathrm{b})$

For AISI 4142, figure 7a shows that in quenched and tempered state, the cyclic stress strain curve is below the monotonic one and the material softens due to cyclic loading. This behavior can only be changed by heat treatment. The AISI 4142 in hardenend state reached stress amplitudes even above the monotonic stress-strain curves, which indicated a cyclic hardening process. However, the cyclic hardening of AISI 4142 in hardenend state led to stress amplitudes in the range of tensile strength. By comparison, in figure $7 \mathrm{~b}$, the metastable austenitic stainless steel AISI 347 a shows a 
significant increase of stress amplitude during the cyclic loading due to $\alpha^{\prime}$-martensite formation. At ambient temperature the CSS curve is at lower total strain amplitudes, due to no pronounced $\alpha^{\prime}$-martensite formation, and below the monotonic stress-strain curve. But at higher $\varepsilon_{a, t}$ due to cyclic hardening, the CSS curve is above the monotonic stress-strain curve. Thus, the tensile strength of $569 \mathrm{MPa}$ was exceeded by $120 \mathrm{MPa}$ to a maximum stress level of $690 \mathrm{MPa}$. These results illustrate clearly a high potential in the cyclic hardening of metastable austenite in comparison to stable steels without deformation induced phase transformation. Because the cyclic loading of metastable austenite led to significant changes in the specimen temperature, the CSS curve of AISI $347 \mathrm{a}$ from tests at $\mathrm{T}=50^{\circ} \mathrm{C}$ is shown in addition to the CSS curve at ambient temperature (AT) in the Fig. 7b. Generally, comparable behavior with cyclic hardening can be seen for both temperatures, but the rate of cyclic hardening in the test at $\mathrm{T}=50^{\circ} \mathrm{C}$ was lower than at AT. The difference in the stress level of the CSS curve at AT to CSS curve at $\mathrm{T}=50{ }^{\circ} \mathrm{C}$ increased with the increasing total strain amplitude until a maximum difference of approximately $100 \mathrm{MPa}$ for $\varepsilon_{\mathrm{a}, \mathrm{t}}$ $=1.6 \%$.

\subsection{Influence of deformation rate and temperature on cyclic induced $\alpha^{\prime}$-martensite formation}

Besides the metastability of austenite and the stressstrain state of microstructure, the strain rate also influences the formation of $\alpha^{\prime}$-marteniste. To investigate this phenomenon, total strain controlled fatigue tests with strain rate in the range $0.01 \% \cdot \mathrm{s}^{-1}<\mathrm{d} \varepsilon_{\mathrm{t}} / \mathrm{dt}<10 \% \cdot \mathrm{s}^{-1}$ were performed. Figure 8a shows the cyclic deformation behavior for different total-strain rates. The specimens from AISI 347 a were cyclically loaded with constant total-strain amplitude $\varepsilon_{\mathrm{a}, \mathrm{t}}=1.2 \%$ and $\mathrm{R}=-1$. (a

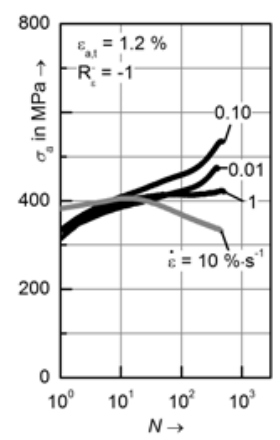

(b)

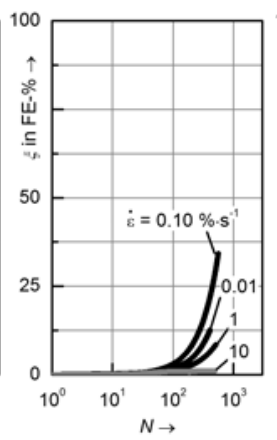

(c)

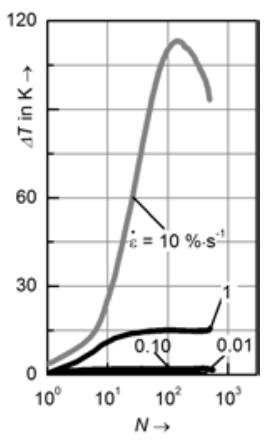

Fig. 8. $\sigma_{\mathrm{a}}-\mathrm{N}(\mathrm{a}), \xi-\mathrm{N}(\mathrm{b})$ and $\Delta \mathrm{T}-\mathrm{N}(\mathrm{c})$ curves from total strain controlled fatigue tests, $\varepsilon_{\mathrm{a}, \mathrm{t}}=1.2 \%, 0.01 \% \cdot \mathrm{s}^{-1}<\mathrm{d} \varepsilon_{\mathrm{t}} / \mathrm{dt}<10 \% \cdot \mathrm{s}^{-1}$, for AISI 347a

For the strain rate up to $\mathrm{d} \varepsilon_{\mathrm{t}} / \mathrm{dt}=1 \% \cdot \mathrm{s}^{-1}$, the cyclic deformation behavior was characterized by a continuous cyclic hardening until sample failure with different specificity. When the strain rate was increased from $0.01 \% \cdot \mathrm{s}^{-1}$ to $0.1 \% \cdot \mathrm{s}^{-1}$, higher stress amplitudes were measured. The ten-time increase in the strain rate led to an increase in the volume fraction of $\alpha^{\prime}$-martensite at the same number of cycles and after failure the specimen loaded with $\mathrm{d} \varepsilon_{\mathrm{t}} / \mathrm{dt}=0.01 \% \cdot \mathrm{s}^{-1}$ had $\xi=13 \mathrm{FE} \%$ and specimen loaded with $0.1 \% \cdot \mathrm{s}^{-1}$ had $\xi=34 \mathrm{FE} \%$ (Fig. $8 \mathrm{~b})$. It should be noted that the change in the temperature was in both tests very small, approximately $\Delta \mathrm{T} \sim 1 \mathrm{~K}$ (Fig. 8c). A further increase in the strain rate to $1 \% \cdot \mathrm{s}^{-1}$ led to an increase in the sample temperature $\Delta \mathrm{T}>14 \mathrm{~K}$. Due to the increase in the sample temperature, the $\alpha$ martensite formation set in later and reached a value of approx. $\xi=8 \mathrm{FE} \%$ at the end of the experiment. At the highest strain rate $\mathrm{d} \varepsilon_{\mathrm{t}} / \mathrm{dt}=10 \% \cdot \mathrm{s}^{-1}$, temperature changes $\Delta \mathrm{T}>100 \mathrm{~K}$ were achieved (Fig. 8c). The enormous increase in temperature after dislocation hardening resulted in cyclic softening of the material until sample failure with complete suppression of $\alpha^{\prime}$-martensite formation. By increasing the strain rate up to $0.1 \% \cdot \mathrm{s}^{-1}$, an increase $\alpha$-martensite formation was observed. When the deformation rate was increased further, the formation of $\alpha$-martensite decreased again since it was not possible to suppress sample heating during the stress. Results from fatigue tests with the strain rate in the range $0.01 \% \cdot \mathrm{s}^{-1}<\mathrm{d} \varepsilon_{\mathrm{t}} / \mathrm{dt}<10 \% \cdot \mathrm{s}^{-1}$ clearly show that an increase of the strain rate led to increases in the formation rate of $\alpha^{\prime}$-martensite, but only if the specimens' temperature was kept approximately constant to ambient temperature $(\Delta \mathrm{T} \sim 1 \mathrm{~K})$. When testing with a strain rate of $1 \% \cdot \mathrm{s}^{-1}, \varepsilon_{\mathrm{a}, \mathrm{t}}=1.2 \%$ and frequency $\mathrm{f} \cong 0.2$ $\mathrm{Hz}$, a change in the temperature led to a comparatively reduced rate of $\alpha^{\prime}$-martensite formation. Therefore, the cyclically induced change in the specimen temperature has to be taken in to consideration by fatigue testing the metastable austenitic steels while significant changes in the formation of $\alpha$ '-martensite, and consequently cyclic deformation behavior, occurred. In the extreme case at higher strain rates or higher frequency, a completely different behavior was observed due to deactivated $\alpha$ martensite formation (see Fig. $8 \mathrm{~b}$ at $\mathrm{d} \varepsilon_{\mathrm{t}} / \mathrm{dt}<10 \% \cdot \mathrm{s}^{-1} / \mathrm{f}$ $\cong 2 \mathrm{~Hz}$ ). In addition, as a function of metastability, small changes in the temperature can significantly influence the formation of $\alpha^{\prime}$-martensite and consequently cyclic deformation behavior. Especially for investigations of high cycle frequency (HCF) behavior up to the limit of number of cycles $\mathrm{N}_{\mathrm{L}}=2 \cdot 10^{6}$, a frequency higher than $2 \mathrm{~Hz}$ is required to obtain the ultimate number of cycles in a justifiable experimental time (e.g. to obtain $\mathrm{N}_{\mathrm{L}}$ with $\mathrm{f}=2 \mathrm{~Hz}$, the test duration is 12 days). Hence, usually stress controlled fatigue tests are performed for investigations of the HCF behavior. Figures 9 and 10 illustrate how the test frequency of 2 $\mathrm{Hz}$ can influence the development of specimen temperature and consequently $\alpha^{\prime}$-martensite formation as well as cyclic deformation behavior. 


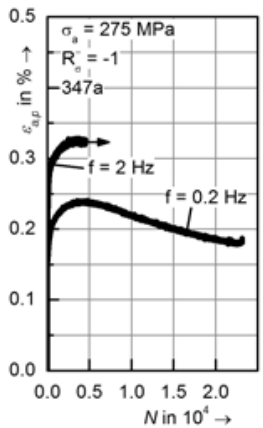

(b)

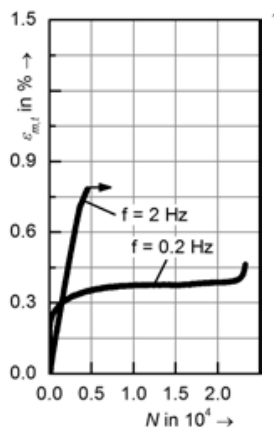

(c)

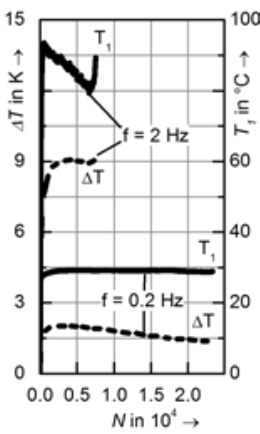

Fig. 9. $\varepsilon_{a, p}-N(a), \varepsilon_{a, p}-N(b)$ and $\Delta T, T_{1}-N(c)$ curves from stress controlled fatigue tests, $\sigma_{\mathrm{a}}=275 \mathrm{MPa}, \mathrm{f}=2$ and $0.2 \mathrm{~Hz}$, for AISI $347 \mathrm{a}$

At $\sigma_{\mathrm{a}}=275 \mathrm{MPa}$, the specimen loaded with $\mathrm{f}=2 \mathrm{~Hz}$ was tested at development temperatures $T_{1}$ (see Fig. 3 ) in the range of $100{ }^{\circ} \mathrm{C}$. The development of plastic strain amplitude versus number of cycle $\left(\varepsilon_{\mathrm{a}, \mathrm{p}}-\mathrm{N}\right.$ curve $)$ showed cyclic softening at specimen failure at $\mathrm{N}_{\mathrm{f}}=7 \cdot 10^{3}$. The same stress amplitude after cyclic softening led to a cyclic hardening process by cyclic loading with the frequency $f=0.2 \mathrm{~Hz}$. The maximum measured temperature $\left(\mathrm{T}_{1}\right)$ in this test was $30{ }^{\circ} \mathrm{C}$. However, to obtain the $\mathrm{N}_{\mathrm{L}}=2 \cdot 10^{6}$ with $\mathrm{f}=0.2 \mathrm{~Hz}, 115$ days of test duration was needed, which is impractical for a systematic investigation of $\mathrm{HCF}$ behavior due to high resource expense at this frequency. Figure 10 shows selected stress-strain hysteresis for both test frequencies. It is clear to see that, the cyclic ratcheting occurred in the austenitic stainless steels by stress controlled fatigue test. The higher the test frequency, the higher the total middle strain (see. Fig. 9b) which led to a reduction of fatigue life. a)
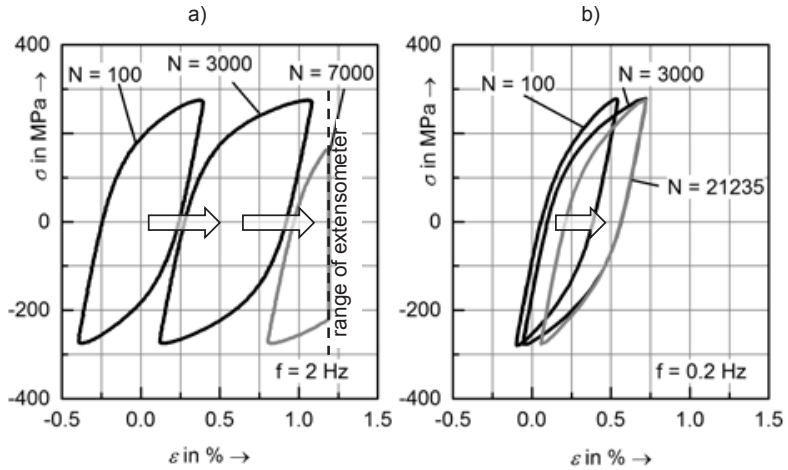

Fig. 10. Stress-strain hysteresis from stress controlled fatigue tests, $\sigma_{\mathrm{a}}=275 \mathrm{MPa}, \mathrm{f}=2$ (a) and $0.2 \mathrm{~Hz}(\mathrm{~b})$, for AISI 347a

\section{Conclusion}

Small changes in the chemical composition of austenitic stainless steels, including changes within batches of the same type, significantly influence the metastability of fcc austenite, which transforms by monotonic and/or cyclic plastic deformation in the more stable bcc martensitic phase. Hence, two-phase microstructures exist with a changing volume fraction and distribution of $\alpha^{\prime}$-martensite by mechanical loading. Consequently, a kind of "dynamically composite material" can develop, with $\alpha^{\prime}$-martensite as reinforcement embedded in the $\gamma$-austenitic matrix. As a result of cyclic plastic deformation, the $\alpha^{\prime}$-martensite forms, which significantly strengthens the material, and the stress amplitude range can achieve a strength higher than the tensile strength of the initial microstructure. The rate of $\alpha^{\prime}$-martensite formation depended on chemical composition, temperature and the stress-strain state of the microstructure. For determination of susceptibility to the formation of deformation-induced $\alpha^{\prime}$-martensite, a method based on dynamically applied local plastic deformation and micro-magnetic measurement was developed. The parameter established as $I_{\xi}$ correlates very well with the grade of $\alpha^{\prime}$-martensite formation during cyclic loading. By investigating the cyclic deformation and transformation behavior of metastable austenitic stainless steels, the frequency or plastic deformation induced self-heating of the specimen has to be taken into account, because the metastability of austenitic microstructures directly depend on temperature.

\section{Acknowledgement}

The authors gratefully acknowledge financial support from Deutsche Forschungsgemeinschaft (DFG) as part of the Collaborative Research Center (SFB) 926, Microscale Morphology of Component Surface.

\section{References}

1. S. Suresh, Fatigue of materials (CUP, 2003)

2. J. Polák, Fatigue of steels in Comprehensive Structural Integrity (Elsevier, 2007)

3. P. Marshall, Austenitic stainless steels (Elsevier, 1984)

4. H. Becker, H. Brandis, W. Küppers, Techn. Berichte 12, 35-54 (1986)

5. T. Angel, J. Iron Steel Inst, 165-174 (1954)

6. G.H. Eichelman, F.C. Hull, Trans. ASM 45, 77-104 (1953)

7. S. Martin, O. Fabrichnaya, D. Rafaja, Mater. Letters 159, 484-488 (2015)

8. J.K. Lai Leuk, C.H. Shek, K.H. Lo, Stainless Steels: An Introduction and Their Recent Developments (Bentham Science Publishers, 2012)

9. J. Man, I. Kubena, M. Smaga, O. Man, A. Järvenpää, A. Weidner, Z. Chlup, J. Polák, Proc. Struct. Integr. 2, 2299-2306 (2016)

10. J. Man, M. Smaga, I. Kubena, D. Eifler and J. Polák, Eng. Fract. Mech. 185, 139-159 (2017)

11. M. Smaga, R. Skorupski, D. Eifler, T. Beck, J. Mater. Res. 32, 4452-4460 (2017)

12. M. Bayerlein, H.-J. Christ, H. Mughrabi, Mat. Sci. Eng. A114, L11-L16 (1989) 
13. M. Smaga, F. Walther, D. Eifler, Mater. Sci. Eng. A 483-484, 394-397 (2008)

14. C. Müller-Bollenhagen, M. Zimmermann, H.-J. Christ, Int J Fatigue 32, 936-942 (2010)

15. M. Droste, C. Ullrich, M. Motylenk, M. Fleischer, A. Weidner, J. Freudenberger, D. Rafaja, H. Biermann, Int J Fatigue 106, 143-152 (2018)

16. F. Hahnenberger, M. Smaga, D. Eifler, Int J Fatigue 69, 36-48 (2014)

17. A. Sorich, M. Smaga, D. Eifler Ad. Mat. Res. 891892, 1231-1236 (2014)

18. C. Grigorescu, P. M. Hilgendorff, M. Zimmermann, C. P. Fritzen, H. J. Christ, Int J Fatigue, 93, 250-271 (2016)

19. M. Smaga, F. Hahnenberger, A. Sorich, D. Eifler, Key Eng. Materials 465, 439-442 (2011)

20. I. Nikitin, M. Besel, Int J Fatigue 30, 2044-2049 (2008)

21. L. Vincent, J.C. Le Roux, S. Taheri, Int J Fatigue 38, 84-91 (2012)

22. D.F. Pessoa, G. Kirchhoff, M. Zimmermann Int J Fatigue, 103, 48-59 (2017)

23. A. Kisko, R.D.K. Misra, J. Talonen, L.P. Karjalainen Mater. Sci. Eng. A 578. 408-416 (2013)

24. J. Talonen, P. Aspegren, P. Hänninen, Mater Sci Technol. 20, 1506-1512 (2004)

25. R.W. Landgraf, Cyclic deformation and fatigue behavior of hardened steels (UIUC, 1968) 